\title{
The "fine-tuning" hypothesis of adult speech to children: Effects of experience and feedback
}

\author{
JOHN NEIL BOHANNON III and ELIZABETH LOTZ STINE \\ Georgia Institute of Technology, Atlanta, Georgia 30332
}

and

\author{
DEBORAH RITZENBERG \\ Emory University, Atlanta, Georgia 30322
}

\begin{abstract}
When adults speak to children, they shorten and simplify their utterances. Bohannon and Marquis (1977) demonstrated that children's verbal feedback could "fine-tune" the length of adult utterances by indicating comprehension or noncomprehension of the preceding adult utterance. The present studies were designed to (1) assess the relative importance of verbal and nonverbal feedback in this process, (2) test the hypothesis that an adult's experience with one child's feedback would generalize to another child, and (3) evaluate the role of previous experience. In Study 1 , subjects were shown videotape recordings of a child giving either comprehension or noncomprehension verbal and nonverbal signals, and the tapes were shown with or without sound. All subjects told a story to a picture of a familiar child (seen in the videotape) and to a picture of a novel child. The length of the utterances addressed to the picture of the familiar child was sensitive to the different verbal signals heard earlier, but this did not generalize to the novel child, nor were the nonverbal signals effective in changing the adults' narratives. In Study 2, subjects answered a questionnaire assessing their experience with children and told a story to each of three pictures, one of an adult and two of children. No significant differences were found in the narratives due to differing experience. However, the speech addressed to the children's pictures was simpler than that addressed to the picture of the adult.
\end{abstract}

When adults speak to children, they simplify and shorten their sentences. This finding is so consistent across the 14 languages currently studied (DePaulo \& Bonvillian, 1978) that Gleason and Weintraub (1978) have called it an "input universal." Moreover, a recent study (Furrow, Nelson, \& Benedict, 1979) has shown that maternal mean length of utterance (MLU) correlates negatively with language gains in holophrastic children. In other words, the shorter the mother's MLU, the more the child's MLU is increased over the duration of the study.

Yet what causes adults to use short sentences? Several studies (Clark-Stewart, VanderStoep, \& Killian, 1979; Benedict, Note 1; Ryan, Note 2) found that maternal MLUs are paced more to the child's receptive language than to either the child's productive speech or the child's age. Cross (1978) found that when children of different ages were matched on comprehension measures, there were no differences among measures of syntactic complexity in their mothers' speech addressed to those children. Gleason (1977) argued that

The authors would like to thank Angela Marquis and Mary Alice Leary for assistance in the gathering and analysis of the data. The study was run under the support of an Emory University research grant to the first author. Reprint requests should be addressed to J. N. Bohannon III, School of Psychology, Georgia Institute of Technology, Atlanta, Georgia 30332. adults rely on children's feedback to "fine-tune" the length and complexity of their utterances to each child's ability to understand. She reasoned that adults often nod or give verbal signals like "yeah, sure" or "ok" when maintaining normal conversation, whereas children rarely do so. It is possible that the lack of such feedback elicits motherese. Indeed, when adults talk to pets (Hirsh-Pasek \& Treiman, in press) or to infants (Sachs, Brown, \& Salerno, 1976), simplified speech occurs in the absence of any verbal feedback.

Bohannon and Marquis (1977) suggested a more active role for listening children. Using a child accomplice, they demonstrated that verbal signals of comprehension and noncomprehension exerted almost perfect moment-to-moment control over adult MLUs. When the child accomplice signaled comprehension, the adults increased their MLUs, and when the child signaled noncomprehension, the adults decreased their MLUs. Verbal feedback from foreign adults also elicits simplified speech during conversation with native adult speakers (Bohannon \& Warren-Leubecker, in press). With few exceptions, most studies extant demonstrate that adults simplify their speech in response to signals indicative of the listener's ability to understand.

Although verbal feedback seems to be a very powerful variable on controlling the length of adult utterances, it is clear that there is more to it. For example, one 
study (Sachs et al., 1976) found that adults simplified their speech when telling stories to a 2-year-old child who the subjects knew was instructed to remain silent throughout all interactions. It is possible that the adults were monitoring the child's nonverbal feedback (e.g., lack of attention, puzzled looks, etc.) during the story narrations. It is also possible that the lack of normal verbal feedback during conversation (instructions notwithstanding) caused the adults to assume noncomprehension (e.g., Gleason, 1977) and, thus, to simplify their speech. The relative effectiveness of the verbal and nonverbal signals could be separated if the adults were given experience with some nonverbal feedback from a child and yet expected no other feedback during their actual story narrations.

Another question comes from the Bohannon and Marquis (1977) study. Bohannon and Marquis found that adults simplified their speech to the child accomplice even when the child signaled comprehension, although not as much as when the child signaled noncomprehension. They concluded that the mere presence of a listening child was sufficient to elicit simple speech. It is possible that the results from both the Bohannon and Marquis (1977) and the Sachs et al.(1976) studies were associated with children's verbal feedback. It can be argued that the subjects in both studies had prior experience with limited receptive language capacities of other children, indicated by their verbal feedback. The use of short MLUs could then have generalized to the silent 2-year-old in the Sachs et al. (1976) study and the comprehending child accomplice in the Bohannon and Marquis (1977) study. This could be assessed by giving adults experience with one child's feedback and then measuring the extent to which that experience generalizes to another child.

Study 1 was done to test the efficacy of verbal vs. nonverbal feedback in the absence of expected verbal feedback. This was accomplished by giving subjects experience with a comprehending or noncomprehending child on a videotape. In another condition, the subjects were allowed only to monitor the child's facial expression (frowns, puzzled looks, gazing about the room, etc.). After viewing the videotape, the subjects were asked to practice telling a story to the child's picture, thus eliminating the expectation of verbal feedback from the listener during narration of the story. Although telling a story to a picture of a child is an artificial situation, in no other way could adults be uninfluenced by either concurrent feedback or the expectation of such feedback. In addition, all the subjects were asked to narrate the same story to a picture of a similar but novel child. If adults shortened their MLUs to both pictures after experience with noncomprehension signals and increased their MLUs to both pictures after experience with comprehension signals, the generalization hypothesis would be supported.

\section{STUDY 1}

\section{Method}

Subjects for Study 1 were 50 undergraduate student volun- teers drawn from classes in psychology. The design for Study 1 was a 2 (types of feedback: comprehension vs. noncomprehension) by 2 (verbal feedback vs. no verbal feedback) by 2 (pictures of children: one with whom they had had experience from the videotape vs. one of a similar but novel child) split-plot factorial design. The first two conditions were variable between groups, and the last (picture) condition was a within-subjects manipulation. There were 10 subjects/condition $(n=40)$. Since it is possible that the subjects may have spoken to the two pictures differently, independently of prior experience, an additional 10 control subjects were asked to speak to the pictures without viewing the videotape.

The videotape-listening episodes consisted of two 1-min recordings of a 9-year-old female accomplice, Stephie, looking at the camera. In both recordings, she wore headphones and sat behind a conspicuously large microphone. For the comprehension conditions, Stephie smiled, gazed directly at the camera without wavering, and gave 10 signals indicating comprehension, 1 signal every $6 \mathrm{sec}$. For the noncomprehension conditions, Stephie frowned, looking puzzled, intermittently gazed about the room, and gave 10 signals indicating comprehension failure, 1 every $6 \mathrm{sec}$. The comprehension signals were "yeah," "unhhung," "sure," and "ok." The noncomprehension signals were "what," "hunh," and "eh," all spoken with a rising terminal pitch. These responses had been found to be effective in eliciting simplified speech with both adult (Bohannon \& Marquis, 1977; Bohannon \& Warren-Leubecker, in press) and child (Bohannon, Warren-Leubecker, \& Thompson, Note 3) listeners. At no time during this experiment did the subjects hear any speech addressed to children. Had they had such experience, any subsequent speech modifications could have been due to the subject's imitating the simple speech of the sample and not to the differences in feedback.

The pictures were $8 \times 10$ in. glossy, full-face photographs in free-standing Plexiglas displays. One picture was of a 9-year-old female, Stephie, who was the girl in the videotape. The other picture was of another 9-year-old female, Joanna, who resembled Stephie. Both girls wore neutral expressions in the photographs.

All subjects were tested individually. They were told that the experiment was about telling stories to children. To "familiarize" themselves with their "target" child, the experimental subjects were asked to view a videotape of a child listening to a story in a "previous" session. The subjects were told that the child was listening to the story over her headphones and speaking to the narrator through the microphone.

The experimental subjects $(N=40)$ then viewed either the 1 -min comprehension tape (10 subjects with sound and 10 subjects with no sound) or the 1-min noncomprehension tape (10 subjects with sound and 10 subjects with no sound). The 10 control subjects were not allowed to view either tape.

All subjects were told that they could "practice" telling the story to pictures of the children before actually confronting the children themselves. They were asked to gaze directly at the picture, imagine the child sitting directly across the table, and tell that child the story. After $2 \mathrm{~min}$ of narration, the subject was stopped and asked to tell the same story to a picture of another child. These stories also lasted $2 \mathrm{~min}$. The order of the pictures, Stephie first or Joanna first, was counterbalanced across subjects. All narratives were recorded on audiotape cassettes for later transcription.

\section{Results}

All the narratives were transcribed and scored for MLU in morphemes using the Bohannon and Marquis (1977) technique. The narratives of the 10 control subjects who were not allowed to view the videotapes did not differ when addressing Stephie's picture (mean = $13.1, \mathrm{SD}=.54)$ vs. Joanna's picture (mean $=13.2$, $\mathrm{SD}=.53$ ). This suggests that there was nothing inherent in the pictures alone that would affect the length of the subjects' utterances. 
A 2 (types of feedback) by 2 (verbal feedback vs. no sound) by 2 (pictures) split-plot factorial analysis of variance was performed on the MLU data of the 40 experimental subjects. The only significant effect was the three-way interaction $[\mathrm{F}(1,36)=13.87, \mathrm{p}<.025]$. This interaction is shown in Table 1.

A Fisher least significant difference (1.s.d.) test showed that the subjects in the no-sound condition with no verbal feedback did not show differences between the conditions (see Table 1). This suggests that within the conditions of Study 1, Stephie's facial expressions were not sufficient to cause the subjects to adjust their MLUs any more than they would have had they not viewed the videotape. This is also reflected in the MLUs addressed to Joanna's picture in the no-sound condition.

The principal source of variance in the three-way interaction resided in the verbal feedback condition. The subjects who viewed the comprehension tape and heard Stephie's signals of comprehension subsequently spoke with an MLU of 14.5 morphemes, which was significantly higher than that spoken by the unexperienced control group (mean $=13.1$ morphemes). The MLU addressed to the picture of the unfamiliar child, Joanna (mean $=13.3$ morphemes), was not significantly different from that of the control group. Subjects who viewed the noncomprehension tape and heard Stephie's verbal signals subsequently spoke with a lower MLU when addressing Stephie's picture (mean $=11.4$ morphemes) than did the control group. This effect was not observed in stories addressed to the unfamiliar Joanna (mean $=12.8$ morphemes). The utterances addressed to Stephie's picture in the verbal feedback conditions differed significantly $(p<.05)$. The lengths of utterances addressed to Joanna's picture, although in the predicted direction, were not significantly different. This suggests that this verbal feedback, indicative of the child's ability to understand, is more powerful in causing MLU adjustments than are facial expressions alone (no-sound condition). In addition, the ease with which the verbal feedback causes MLU adjustments to the picture of the familiar child does not seem to transfer to the pictures of other children.

Table 1

Group MLU Addressed to Children's Pictures

\begin{tabular}{lrccc}
\hline & \multicolumn{2}{c}{ Verbal Feedback } & \multicolumn{2}{c}{ No Sound } \\
\cline { 2 - 5 } & $\begin{array}{c}\text { Familiar } \\
\text { Child }\end{array}$ & $\begin{array}{c}\text { Novel } \\
\text { Child }\end{array}$ & $\begin{array}{c}\text { Familiar } \\
\text { Child }\end{array}$ & $\begin{array}{c}\text { Novel } \\
\text { Child }\end{array}$ \\
\hline \multicolumn{5}{c}{ Comprehension Feedback } \\
Mean & 14.5 & 13.4 & 12.8 & 12.9 \\
SD & 2.3 & 3.5 & 1.1 & .8 \\
& \multicolumn{5}{c}{ Noncomprehension } \\
Mean & 11.4 & 12.6 & 13.2 & 12.5 \\
SD & 1.5 & 2.6 & 2.1 & 1.6 \\
\hline
\end{tabular}

Note-Entries reflect results of Fisher's least significant difference test: Any mean difference greater than or equal to 1.3 is significant $(p<.05)$.

\section{Discussion}

The hypothesis that simple speech occurring in the absence of specific verbal feedback is due to children's facial cues was not supported. In light of these findings, the results of the Sachs et al. (1976) study may be more specifically interpreted by saying that the simplifications were perhaps due to lack of expected verbal feedback (Gleason, 1977) or to the adult's expectation of linguistic incompetence, rather than to the facial expressions per se. Having created a situation in which the listener could expect no verbal feedback, Study 1 separated out these effects, demonstrating that differing facial expressions alone had no effect. At this point, one caveat may be offered. This is not to say that nonverbal feedback plays no role whatsoever. One possible reason for the ineffectiveness of the nonverbal feedback is that by removing it from the context of the ongoing conversation, we caused the subjects to be unsure as to the meaning of the puzzled looks, and hence, no adjustments occurred.

The generalization hypothesis was likewise not supported. Significant and appropriate adjustments that occurred to the picture of the familiar child, Stephie, simply did not occur when subjects talked to the picture of the similar but novel child, Joanna. It is possible that the meager amount of feedback received by our subjects was insufficient to counter the habits of many prior experiences with children's feedback. Yet if that was the case, there should not have been any adjustments to Stephie's picture. In fact, the MLUs addressed to Stephie's picture in the verbal comprehension condition approximate those previously reported to occur between adults (MLU = 14.2 morphemes; Bohannon \& Marquis, 1977).

The last finding of note in Study 1 was that adults reduced the complexity of their speech to the children's pictures without any experience with the child in the picture. One problem with this conclusion is that adults may address short utterances to any photograph of a face, even a photograph of another adult. Study 2 assessed the MLUs directed to pictures of an adult vs. pictures of children to answer this question. In addition, the subjects in Study 2 were asked about their experience in conversing with children. Since the specific feedback given in Study 2 was insufficient to warrant generalization, an assessment of the subjects' broader experience may show a relationship to the MLUs they address to the pictures of children.

\section{STUDY 2}

\section{Method}

Subjects for Study 2 were 34 undergraduate volunteers from psychology classes. Each subject was asked to report the number and ages of their younger siblings (if any) and any experiences they may have had that required conversing with young children (e.g., as baby-sitter, camp counselor, etc.). In addition, the subjects were asked to rate themselves on a 7-point scale as to the amount of experience they had speaking to children.

The picture stimuli were the $8 \times 10$ in. glossy, full-face photographs in free-standing Plexiglas displays. The photographs were of a 32-year-old female, Judy, her 9-year-old daughter, Stephie, and her 3-year-old daughter, Rebecca. The expressions in all photographs were neutral.

The subjects were tested individually on all three pictures, with the order of picture presentation counterbalanced across subjects. Each subject was asked to imagine that the person in the picture was seated across the table and to tell that person the story of the Wizard of Oz. The subjects were also instructed to gaze directly at the pictures during story narration. All stories were terminated at the end of $2 \mathrm{~min}$ and were recorded on audio-cassette tape. The narratives were transcribed and scored for MLU in morphemes, using the Bohannon and Marquis (1977) technique.

\section{Results}

To test the hypothesis that gross amount of experi- 
ence in conversing with children affects story narratives, intercorrelations were computed among the subjects' MLUs, number of younger siblings, special experience with children (yes $=1$, no $=0$ ), and self-rating scores. Although the subjects' self-ratings correlated with the number of their younger siblings $(r=.38, p<.05)$ and with their reported special experience $(\mathrm{r}=.41, \mathrm{p}<.05)$, none of those measures correlated with the length of their utterances addressed to the pictures of the children.

To test for a nonlinear relationship, the subjects' data were parceled into three groups on the basis of their self-ratings: (1) a below-average group, with self-ratings from one to three $(n=9) ;(2)$ an average group, with a self-rating of four $(n=7)$; and (3) an above-average group, with self-ratings from five to seven $(\mathrm{n}=18)$. Using this grouping scheme, a 3 (self-rated experience groups) by 3 (pictures) split-plot least-squares analysis of variance was performed on the MLU data. There was no significant effect of self-rated experience. However, the subjects reduced the length of their utterances when talking to the pictures of the children $[F(2,45)=4.71$, $\mathrm{p}<.01$; MLU for the picture of adults $=17.7$, MLU for the picture of the 9-year-old $=13.2$, and MLU for the picture of the 3-year-old $=13.9]$. Fisher's 1.s.d. test indicated that the MLUs directed to the picture of the adult, Judy, were longer than those to either child. Those to the children did not differ significantly.

\section{Discussion}

It is clear that the short utterances addressed to the children's pictures were related to the faces of the children and not to the fact that adults address short MLUs to all pictures. The adults in Study 2 simplified their sentences only to the pictures of children, and not to the picture of the adult. On the other hand, the subjects did not differentiate between the pictures of the younger and older children in the length of the utterances addressed to each picture, even though the younger child was clearly younger. It is possible that the adults spoke to the pictures in a manner consistent with their expectations of the language competence of the listener pictured in the photograph.

The hypothesis that general experience in conversing with children is related to the simplifications directed to the pictures was not supported. The self-ratings correlated with the number of the subjects' younger siblings and other relevant experience, such as baby-sitting. However, none of these measures correlated with MLU. Although the question may be raised as to whether something so pervasive in the lives of most human beings as "experience with children" can be measured so simply, there are hints in other studies that parallel these findings. Snow (1972) found that all adults simplified their speech when talking to children, regardless of whether they had children of their own. Shatz and Gelman (1973) found that 4-year-olds simplify their speech to 2-year-olds. Bohannon and Warren-Leubecker (Note 3) found that even 3-year-olds used shorter MLUs when their listeners gave obvious cues of comprehension difficulty. These findings, in conjunction with Studies 1 and 2 , suggest that the simplification in speech to children may be a phenomenon so basic to the process of conversation that the amount of experience in conversation is irrelevant.

On the other hand, it is possible that the face of the child had an effect on the speakers in the present study. Sternglanz, Grey, and Murakami (1977) found that the features of a child's face (e.g., large eyes and forehead) elicited consistent positive regard from a sample of college students. Sternglanz et al. described their findings from an ethological perspective. It may be that another consistent impulse elicited by a child's face is to simplify any utterances addressed to that face. In fact, a general and immediate simplification upon first addressing an unfamiliar child would enhance the possibility that the child would comprehend. After the initial utterance, the complexity of the adults' utterances could then be shaped and "fine-tuned" to the child's level by verbal feedback. In this light, excessive generalization from other children may hamper adults' ability to adjust the complexity and length of their speech to the needs of different child listeners.

\section{REFERENCE NOTES}

1. Benedict, H. The effects of conversational context on mother's speech to children. Paper presented at the meeting of the Southeastern Conference on Human Development, Atlanta, April 1978.

2. Ryan, J. P. Mother's perception of children's linguistic ability. Paper presented at the Southeastern Conference on Human Development. Atlanta, April 1978.

3. Bohannon, J. N., Warren-Leubecker, A., \& Thompson, D. Context, feedback and four-year-olds: How children talk to guys ' $n$ dolls. Paper presented at the meeting of the Society for Research in Child Development, Boston, April 1981.

\section{REFERENCES}

Bohannon, J. N., \& Marquis, A. L. Children's control of adult speech. Child Development, 1977, 48, 1002-1008.

Bohannon, J. N., \& Warren-Leubecker, A. Effects of expectation and feedback on speech to foreigners. Journal of Psycholinguistic Research, in press.

Clark-Stewart, K. A., VanderStoep, L. P., \& Killian, G. A. Analysis and replication of mother-child relations at two years of age. Child Development, 1979, 50, 777-793.

Cross, T. Mother's speech and its association with the rate of linguistic development in young children. In $\mathrm{N}$. Waterson \& C. E. Snow (Eds.), The development of communication. New York: Wiley, 1978.

DePaulo, B. M., \& Bonvillian, J. D. The effect on language development of the special characteristics of speech addressed to children. Journal of Psycholinguistic Research, 1978, 7, 289-311.

Furrow, D., Nelson, K., \& Benedict, H. Mother's speech to children and syntactic development: Some simple relationships. Journal of Child Language, 1979, 6, 423-442.

Gle ason, J. B. Some notes on feedback. In C. E. Snow \& C. A. Ferguson (Eds.), Talking to children: Language input and acquisition. Cambridge, Mass: Cambridge University Press, 1977.

Gleason, J. B., \& Weintraub, S. Input language and the acquisition of communicative competence. In K. E. Nelson (Ed.), Children's language. New York: Gardiner Press, 1978.

Hirsh-PaseK, K., \& Treiman, R. Doggerel: Motherese in a new context. Journal of Child Language, in press.

Sachs, J., Brown, R., \& Sale Rno, R. Adult's speech to children. In Von Raffler-Engle \& Y. Lebrun (Eds.), Baby talk and infant speech. Lisse, Netherlands: Swets \& Zeitlinger, 1976.

Shatz, M., \& Gelman, R. The development of communication skills: Modifications in the speech of young children as a function of listener. Monographs of the Society for Research in Child Development, 1973, 38(Serial No. 152).

SNow, C. E. Mothers' speech to children learning language. Child Development, 1972, 43, 549-565.

Sternglanz, S., Grey, J., \& Murakami, M. Adult preferences for infant facial features: An ethological approach. Animal Behavior, 1977, 25, 108-115.

(Received for publication January 31, 1982.) 